\title{
STRUKTUR ANATOMI, SIFAT FISIS DAN MEKANIS KAYU KUMEA BATU
}

\author{
(Anatomical Structure, Physical and Mechanical Properties \\ of Kumea Batu Wood)
}

Oleh/By :

Mody Lempang \& Muhammad Asdar

\begin{abstract}
This research was carried out to examine the anatomical structure/characteristics, and physical and mechanical properties of lesser-known kumea batu (Manilkara merrilliana H.J.L.) wood. Wood samples of this species was taken from naturalproduction forest growing in Lampia Sub Regency, East Luwu District, West Sulawesi Province.

The results revealed that kumea batu wood had a reddish light brown colour of sapwood and reddish brown colour of heartwood. Wood growth rings were diffuse and sometimes appeared clearly with figures of decorative surface in form of parallel lines on radial section with straight grain, fine texture, and glossy surface. In averages, fiber length was $677.55 \mu \mathrm{m}$, fiber diameter $22.15 \mu \mathrm{m}$, lumen diameter $1.94 \mu \mathrm{m}$, and fiber-wall thickness $10.10 \mu \mathrm{m}$. Assessment on the derived values of fiber dimensions for pulp/paper manufacture revealed that kumea batu wood belonged to class IV. This wood species was remarkably heavy (specific gravity 0,92), considerably high in dimensional shrinkage. It had ultimate bending strength at $612.72 \mathrm{~kg} / \mathrm{cm}^{2}$, compression strength parallel to grain $402.28 \mathrm{~kg} / \mathrm{cm}^{2}$ and was classified in wood strength as class II.
\end{abstract}

Keyword: Wood, Manilkara merrilliana, anatomical structure, physical and mechanicalproperties.

\begin{abstract}
ABSTRAK
Penelitian ini dilakukan untuk mengamati struktur/karakteristik anatomi, dan sifat fisis mekanis kayu kurang dikenal jenis kumea batu (Manilkara merrilliana H.J.L.). Sampel kayu dari jenis ini diambil dari hutan alam produksi di Kecamatan Lampia Kabupaten Luwu Timur, Propinsi Sulawesi Selatan.

Hasil penelitian menunjukkan bahwa kumea batu memiliki kayu gubal berwarna coklat muda kemerahan dan teras berwarna coklat kemerahan. Lingkar tumbuh samar-samar dan terkadang jelas serta menampakkan corak yang indah berupa garis-garis sejajar pada potongan radial, serat lurus, tekstur halus dan permukaan kayu mengkilap. Panjang serat $677,55 \mu \mathrm{m}$, diameter serat $22,15 \mu \mathrm{m}$, diameter lumen 1,94 $\mu \mathrm{m}$, tebal dinding $10,10 \mu \mathrm{m}$ dan semua nilai turunan serat tergolong dalam kelas IV untuk bahan baku pulp/kertas. Kayu kumea batu sangat berat (berat jenis 1.07) dengan penyusutan sangat tinggi, keteguhan lentur pada batas patah $1,557.68 \mathrm{~kg} / \mathrm{cm}^{2}$, keteguhan tekan sejajar serat $491.35 \mathrm{~kg} / \mathrm{cm}^{2}$ dan tergolong kayu kelas kuat II.
\end{abstract}

Kata Kunci: Kayu, kumea batu, struktur anatomi, sifat fisis dan mekanis.

\section{PENDAHULUAN}

${ }^{1)}$ Peneliti pada Balai Penelitian Kehutanan, Makasar 
Salah satu karakteristik kayu yang paling penting adalah dapat diperbaharui. Bahkan kayu tidak akan habis asal penggunaannya didasari dengan pandangan masa depan dan perencanaan jangka panjang, yaitu antara lain besarnya konsumsi kayu disertai dengan usaha menumbuhkan kembali pohonnya. Semakin berkurangnya sumber bahan bakar fosil, sumber alternatif seperti kayu yang secara terus menerus diperbaharui melalui proses biologis (oleh alam) menjadi sangat penting.

Kayu merupakan bahan mentah yang sangat tua. Beribu-ribu tahun yang lalu, ketika hutan lebat menutupi kawasan yang luas dipermukaan bumi, orang-orang primitif menggunakan kayu untuk bahan bakar dan perkakas. Namun, di sisi lain kayu merupakan bahan dasar yang sangat moderen. Kubah-kubah kayu yang besar dan perabot-perabot kayu yang indah membuktikan kegunaan dan keindahannya. Bahkan dapat berupa dalam alih bentuk seperti kayu lapis, papan partikel, pulp dan kertas, serat, film, aditif, dan banyak produk-produk lain. Sehingga, tidaklah berlebihan jika dikatakan,bahwa kayu adalah salah satu produk alam yang sangat penting.

Indonesia memiliki potensi hutan sekitar 4.000 jenis kayu, dan diperkirakan 400 jenis diduga akan memegang peranan penting dikemudian hari. Dari 400 jenis tersebut 258 jenis yang diperdagangkan, paling tidak secara lokal. Sementara sampai tahun 1986 baru sekitar 95 jenis yang telah diteliti sifat dasarnya secara lengkap dan sifat dasar kayu lainnya baru sebagian diteliti (Mandang dan Martawijaya, 1987). Oleh karena itu, penelitian tentang sifat dasar kayu, khususnya kayu kurang dimanfaatkan penting dilakukan. Kecenderungan pemakaian kayu akan terus meningkat, baik untuk keperluan struktural maupun industri. Hal ini perlu diimbangi dengan pengetahuan jenis kayu, sifat dan cara pengolahan kayu agar kayu tersebut dapat digunakan secara efektif dan efisien. Untuk memenuhi kebutuhan kayu yang semakin meningkat di masa yang akan datang dan untuk memperoleh nilai manfaat kayu yang sebesar-besarnya dari hutan saat ini tidak dapat lagi dipisahkan dari perhatian terhadap pemanfaatan jenis kayu dari jenis pohon kurang dikenal. Namun sebelum menggunakan kayu dari jenis pohon kurang dikenal untuk tujuan tertentu, terlebih dulu perlu dilakukan penelitian mengenai sifat dasar dan kemungkinan pemanfaatan kayu dari jenis pohon tersebut.

Ketepatan pemilihan jenis kayu untuk sesuatu pemakaian memerlukan pengetahuan tentang sifat dasarnya. Sifat dasar tersebut, diantaranya berat jenis, kekuatan, dan stabilitas dimensi. Sifat tersebut bisa dipengaruhi oleh sifat atau karakteristik anatomi kayu. Sebagai contoh pohon yang membentuk kayu dengan berat jenis tinggi dipengaruhi antara lain oleh dinding sel yang tebal dan kadar zat ekstraktif. Hal tersebut sangat bernilai bagi pengolahan produk-produk kayu gergajian struktural. Sedangkan jenis pohon yang menghasilkan kayu dengan berat jenis rendah dipengaruhi oleh dinding sel yang tipis dan rongga sel, jumlah dan ukuran pori yang besar. Jenis ini cocok sebagai bahan baku pembuatan pulp dan kertas. Jadi, sifat dasar kayu ini penting dipahami agar didalam proses pengolahan, pengangkutan, maupun penggunaannya dapat dilakukan secara saksama sehingga tidak terjadi pemborosan bahan, waktu, tenaga maupun biaya.

Penelitian ini bertujuan untuk mempelajari struktur anatomi, sifat fisis dan mekanis kayu kumea batu agar dapat ditetapkan kelas dimensi serat berdasarkan nilai turunan serat, dan kelas kuat berdasarkan sifat fisik dan mekanik dan merekomendasikan penggunaannya.

\section{BAHAN DAN METODE}


JURNAL Penelitian Hasil Hutan Vol. 26 No. 2, Juni 2008: 138-147

\section{A. Bahan}

Bahan yang digunakan sebagai contoh uji dalam penelitian ini adalah jenis kayu Sulawesi yaitu kumea batu (Manilkara merrilliana H.J.L.) sebanyak tiga pohon. Penelitian dilaksanakan dari bulan Juni sampai bulan Desember 2005. Contoh uji diambil dari hutan produksi alam di Lampia, Kabupaten Luwu Timur, Propinsi Sulawesi Selatan. Pengamatan struktur anatomi dan pengujian sifat fisis dilaksanakan pada laboratorium Balai Penelitian dan Pengembangan Kehutanan Sulawesi di Makassar, sementara pengujian sifat mekanis dilaksanakan di laboratorium Struktur Bahan Fakultas Teknik Jurusan Sipil, Universitas Hasanuddin.

\section{B. Metode}

Pengamatan struktur anatomi kayu meliputi ciri umum (makroskopis) dan ciri anatomi (mikroskopis). Ciri umum kayu diamati pada contoh kayu utuh maupun yang telah diketam. Penelaahan dilakukan menurut prosedur yang disusun oleh Martawijaya dan Kartasudjana (1977), yaitu meliputi warna kayu, tekstur, arah serat, kilap, kesan raba dan gambar. Ciri anatomi diamati pada preparat maserasi dan sayatan pada bidang lintang, radial dan tangensial yang telah diwarnai dengan safranin menurut metode Sass (1958). Ciri anatomi tersebut meliputi dimensi serat, dimensi pembuluh, susunan dan sebaran pembuluh, susunan parenkim, susunan dan bentuk jari-jari, adanya saluran interselular, silika, dan lain-lain sesuai dengan $I A W A$ list (Wheeler, et. al., 1989).

Pengujian sifat fisis dan mekanis dilakukan dengan mengikuti standar JIS (Japan Industrial Standard). Pengujian sifat fisis kayu meliputi kadar air, berat jenis dan penyusutan mengikuti JIS Z 2101, Z 2102 dan Z 2103, sedangkan pengujian sifat mekanis meliputi keteguhan lentur statik, keteguhan tekan sejajar serat dan keteguhan tekan tegak lurus serat, kekerasan sisi dan keteguhan pukul. mengikuti JIS Z 2113, Z 2111, Z 2116 dan 2117 (Anonim, 2003).

\section{HASIL DAN PEMBAHASAN}

\section{A. Stuktur Anatomi}

Ciri Umum

Warna: kayu teras berwarna coklat kemerahan, dapat dibedakan dengan kayu gubal yang berwarna coklat muda kemerahan. Kayu gubal lebarnya mencapai 3,4 cm dengan proporsi kayu teras hanya sekitar 50\% berdasarkan volume. Rendahnya persentase kayu teras kumea batu mungkin disebabkan oleh karena pohon yang ditebang masih berada pada tahap pertumbuhan yang cepat. Corak : bergaris-garis. Tekstur: halus. Kilap: mengkilap. Kesan raba: licin. Kekerasan: keras.

Ciri Anatomi 
Lingkar tumbuh: samar-samar (tidak jelas). Pori: baur, soliter dan berganda radial dan tangensial 2-4, perforasi sederhana, diameter rata-rata 69,15 $\mu \mathrm{m}(30$ - $105 \mu \mathrm{m})$, frekuensi pori 11,38 per $\mathrm{mm}^{2}$ (5-16 per $\left.\mathrm{mm}^{2}\right)$, panjang pori $83.06 \mu \mathrm{m}(45-135 \mu \mathrm{m})$, berisi tylosis dan endapan coklat kemerahan. Parenkim: difus (menyebar), tangensial pendek sampai panjang dan berbentuk jala dengan frekuensi 5-8 baris per $\mathrm{mm}$ arah radial. Jari-jari: heteroselular, berseri 1 (kadang sampai 4) dengan tinggi rata-rata 477,80 $\mu \mathrm{m}(150-1500 \mu \mathrm{m})$, lebar jari-jari $16 \mu \mathrm{m}$ $(7,5-30 \mu \mathrm{m})$, frekuensi 12 per $\mathrm{mm}$ ( 7 - 15 per $\mathrm{mm})$. Serat: panjang rata-rata 677,55 $\mu \mathrm{m}(280$ $910 \mu \mathrm{m})$, diameter $22,15 \mu \mathrm{m}(15-32,5 \mu \mathrm{m})$, diameter lumen $1,94 \mu \mathrm{m}(0-5 \mu \mathrm{m})$ dan tebal dinding serat $10,10 \mu \mathrm{m}(6-15 \mu \mathrm{m})$.



a
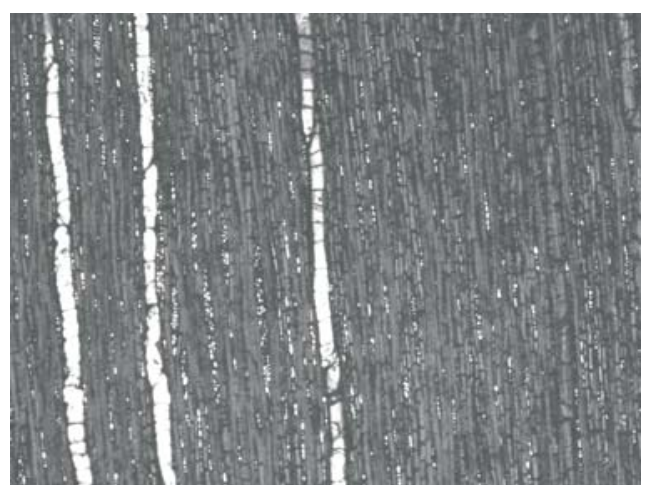

$\mathrm{b}$

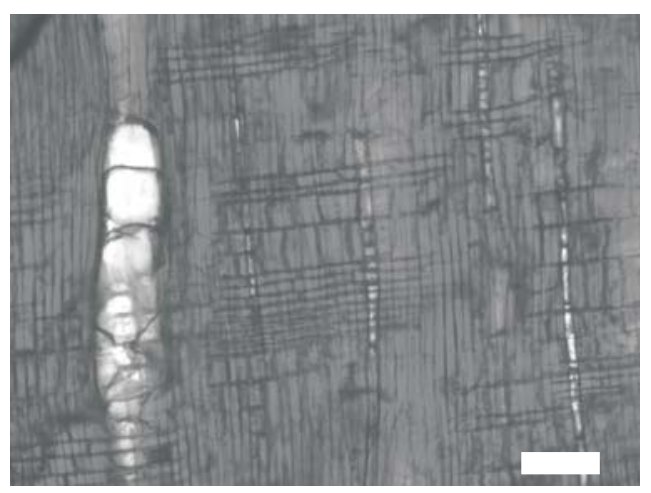

C

Gambar 1. Kumea batu (Manilkara merrilliana H.J.L.) Figure 1. Kumea batu (Manilkara merrilliana H.J.L.)

a. Penampang lintang (Transversal surface), skala (scale) $250 \mu \mathrm{m}$

b. Penampang tangensial (Tangential surface), skala (scale) $250 \mu \mathrm{m}$

c. Penampang radial (Radial surface), skala (scale) $100 \mu \mathrm{m}$ 
jURNAL Penelitian Hasil Hutan Vol. 26 No. 2, Juni 2008: 138-147

Nilai rata-rata, standar deviasi, nilai maksimum dan minimum karakteristik anatomi kayu kumea batu disajikan pada Tabel 1.

Tabel1. Nilai rata-rata, standar deviasi, nilai maksimum dan minimum karakteristik anatomi kayu kumea batu.

Table 1. Average, standard deviation, maximum and minimum of anatomical characteristics of Manilkara merrilliana wood.

\begin{tabular}{|l|c|c|c|c|c|}
\hline $\begin{array}{c}\text { Karakteristik anatomi } \\
\text { (Anatomical } \\
\text { characteristics) }\end{array}$ & $\begin{array}{c}\text { Satuan } \\
\text { Unit) }\end{array}$ & $\begin{array}{c}\text { Rata-rata } \\
\text { (Average) }\end{array}$ & $\begin{array}{c}\text { Standardeviasi } \\
\text { (Standard deviation) }\end{array}$ & $\begin{array}{c}\text { Minimum } \\
\text { (Minimum) }\end{array}$ & $\begin{array}{c}\text { Maksimum } \\
\text { (Maximum) }\end{array}$ \\
A. Serat (Fibers) & & & & & \\
Panjang (length) & $\mu \mathrm{m}$ & 677,55 & 85,22 & 280,00 & 910,00 \\
Diameter (diameter) & $\mu \mathrm{m}$ & 22,14 & 3,75 & 15,00 & 32,50 \\
Lumen (lumina) & $\mu \mathrm{m}$ & 1,94 & 1,16 & 0,00 & 5,00 \\
Tebal dinding (wall & $\mu \mathrm{m}$ & 10,10 & 1,96 & 6,00 & 15,00 \\
thickness) & & & & & \\
Pori (Vessels) & & & & & \\
Panjang (length) & $\mu \mathrm{m}$ & 83,06 & 19,11 & 45,00 & 135,00 \\
Diameter(diameter) & $\mu \mathrm{m}$ & 69,15 & 14,95 & 30,00 & 105,00 \\
Frekuensi(frequency) & $\mathrm{v} / \mathrm{mm}{ }^{2}$ & 11,38 & 2,25 & 5,00 & 16,00 \\
Gabungan(grouping) & $\%$ & 25,43 & 6,44 & 11,76 & 40,00 \\
C. Jari-jari(Rays) & & & & & \\
Frekuensi(Frequency) & $\mathrm{r} / \mathrm{mm}$ & 12,14 & 1,78 & 7,00 & 15,00 \\
Tinggi(Height) & $\mu \mathrm{m}$ & 477,80 & 195,49 & 150,00 & 1500,00 \\
Lebar(width) & $\mu \mathrm{m}$ & 16,00 & 3,94 & 7,50 & 30,00 \\
\hline
\end{tabular}

Keterangan (remarks):

$\mathrm{v} / \mathrm{mm}^{2}$ : Jumlah pori per milimeter persegi (Number of vesselsper square milimetre)

$\mathrm{r} / \mathrm{mm}$ : Jumlah jari-jari per milimeter (Number of raysper milimetre)

Nilai turunan serat kayu kumea batu berdasarkan Departemen Pertanian (Anonim, 1976): panjang serat tergolong kelas IV, bilangan Runkel (kelas IV), daya tenun (kelas IV), rasio Muhlstep (kelas IV) dan koefisien kekakuan (kelas IV). Secara keseluruhan dimensi serat kayu kumea batu tergolong kelas IV untuk bahan baku pulp dan kertas.

Kayu kumea batu yang diteliti memiliki memiripan ciri dengan $M$. fasciculata, $M$. hexandra, M. kauki, M. littoralis (Kurz) Dubard dan M. Zapota (Soerianegara and Lemmens, 1994). Perbedaannya terletak pada panjang serat yang jauh lebih pendek pada kayu kumea batu.

\section{B. Sifat Fisis Mekanis}

Pengukuran sifat fisis kayu kumea batu dilakukan pada kondisi basah, kering udara dan kering tanur. Penetapan nilai berat jenis, yakni berat jenis basah berdasarkan berat kering tanur dan volume basah, berat jenis kering udara berdasarkan berat dan volume masingmasing dalam keadaan kering udara, dan berat kering tanur (kerapatan) berdasarkan berat dan volume masing-masing dalam keadaan kering tanur. Nilai rata-rata hasil pengukuran sifat fisis dapat dilihat pada Tabel 2 berikutini: 
Tabel 2. Rata-rata sifat fisis kayu kumea batu (Manilkara merrilliana)

Table 2. Average of physicalproperties of kumea batu (Manilkara merrilliana).

\begin{tabular}{|c|c|c|c|c|c|c|}
\hline \multirow[t]{2}{*}{ No. } & \multirow[t]{2}{*}{$\begin{array}{c}\text { Sifat fisis } \\
\text { (Physical properties) }\end{array}$} & \multirow[t]{2}{*}{$\begin{array}{l}\text { Satuan } \\
\text { (Unit) }\end{array}$} & \multicolumn{3}{|c|}{$\begin{array}{l}\text { Ketinggian posisi kayu dalam } \\
\text { batang dari permukaan tanah } \\
\text { (Height of wood position in the } \\
\text { trunk, from the ground) }\end{array}$} & \multirow[t]{2}{*}{$\begin{array}{l}\text { Rata-rata } \\
\text { (Average) }\end{array}$} \\
\hline & & & $\begin{array}{l}\text { Pangkal } \\
\text { (Bottom) }\end{array}$ & $\begin{array}{l}\text { Tengah } \\
\text { (Middle) }\end{array}$ & $\begin{array}{l}\text { Ujung } \\
(T o p)\end{array}$ & \\
\hline 1. & $\begin{array}{l}\text { Kadar air basah } \\
\text { (Green moisture content) }\end{array}$ & $\%$ & 45,40 & 47,70 & 50,35 & 47,82 \\
\hline 2. & $\begin{array}{l}\text { Kadar air kering udara } \\
\text { (Air dry moisture content) }\end{array}$ & $\%$ & 16,67 & 16,47 & 16,16 & 16,43 \\
\hline 3. & $\begin{array}{l}\text { Berat jenis nominal basah } \\
\text { (Nominal green specific gravity) }\end{array}$ & - & 0,89 & 0,87 & 0,87 & 0,87 \\
\hline 4. & $\begin{array}{l}\text { Berat jenis kering udara } \\
\text { (Air dry specific gravity) }\end{array}$ & - & 0,95 & 0,91 & 0,89 & 0,92 \\
\hline $\begin{array}{l}5 . \\
6 .\end{array}$ & $\begin{array}{l}\text { Berat jenis kering tanur/oven } \\
\text { (Oven dry specific gravity) } \\
\text { Penyusutan daribasah ke } \\
\text { keringudara } \\
\text { (Shrinkage from green to air dry) }\end{array}$ & - & 1,08 & 1,02 & 1,02 & 1,04 \\
\hline & Radial (Radial) & $\%$ & 2,18 & 1,57 & 1,46 & 1,74 \\
\hline 7. & $\begin{array}{l}\text { Tangensial (Tangential) } \\
\text { Penyusutan dari basah ke kering } \\
\text { tanur } \\
\text { (Shrinkage from green to oven dry) }\end{array}$ & $\%$ & 3,21 & 2,84 & 2,49 & 2,84 \\
\hline & Radial (Radial) & $\%$ & 6,72 & 6,22 & 6,09 & 6,34 \\
\hline & Tangensial (Tangential) & $\%$ & 9,63 & 9,34 & 9,11 & 9,36 \\
\hline
\end{tabular}

Hasil pengujian sifat fisis seperti pada Tabel 2 di atas menunjukkan bahwa kadar air basah rata-rata $47,82 \%$, ini menunjukkan bahwa kadar air basah kumea batu cukup rendah. Berat jenis kering udara rata-rata 0,92 . Berdasarkan klasifikasi kayu menurut Dumanauw (1982), maka kayu tersebut termasuk kayu sangat berat karena mempunyai berat jenis kering udara $>0,90$. Kumea batu tergolong kayu sangat berat dengan penyusutan dari keadaan basah ke kering udara rata-rata 2,84\% (tangensial) dan dari keadaan basah ke kering tanur rata-rata 9,36\% (tangensial), ini menunjukkan bahwa kumea batu tergolong kayu yang memiliki penyusutan sangat tinggi. Kayu yang memiliki penyusutan tinggi pada umumnya adalah jenis yang mempunyai dinding serat yang tebal dan kayu kumea batu mempunyai diding serat yang sangat tebal yaitu rata-rata $10,10 \mu \mathrm{m}(6-15 \mu \mathrm{m})$ Perbandingan penyusutan tangensial dan radial ( $\mathrm{T} / \mathrm{R}$ ) sebesar 1,48 menunjukkan bahwa kayu tersebut memiliki kestabilan dimensi yang cukup rendah. Panshin dan de Zeeuw (1980) mengemukakan bahwa nilai banding $\mathrm{T} / \mathrm{R}$ yang makin mendekati 1,00 berarti stabil. Kayu kumea batu dalam bentuk papan atau balok dikeringkan secara alami berubah bentuk (melengkung) dan cacat retak yang cukup berat. Oleh karena itu, pengeringan kayu tersebut harus dilakukan dengan hati-hati. Demikian juga bila menggunakan kayu kumea batu untuk pembuatan produk yang membutuhkan nilai kestabilan dimensi yang cukup tinggi, misalnya untuk mebel dan barang 
jURNAL Penelitian Hasil Hutan Vol. 26 No. 2, Juni 2008: 138-147

kerajinan, maka kemungkinan retak dan perubahan bentuk harus dipertimbangkan secara seksama dalam pengolahan/pengerjaan kayu agar kualitas produk yang dihasilkan tidak mengecewakan.

Penyusutan kayu kumea yang tinggi disebabkan oleh tingginya kerapatan kayu. Menurut Haygreen dan Bowyer (1996), semakin tinggi kerapatan kayu, semakin banyak kecenderungannya untuk menyusut. Salah satu penentu tingginya kerapatan kayu kumea menurut Panshin dan de Zeeuw (1980) adalah tebal dinding sel. Semakin tebal dinding sel khususnya serabut dan lumen yang kecil, maka kayu tersebut cenderung memiliki kerapatan yang tinggi.

Selanjutnya hasil pengujian sifat mekanis kayu kumea batu disajikan pada Tabel 3.

Pada umumnya klasifikasi kekuatan kayu di Indonesia didasarkan pada berat jenis, keteguhan lentur pada batas patah dan keteguhan tekan sejajar serat. Sifat-sifat mekanis lainnya juga penting diketahui dalam hubungannya dengan pengolahan dan pemanfaatan kayu untuk keperluan tertentu. Berdasarkan nilai berat jenis kering udara $(0,92)$, keteguhan lentur pada batas patah $\left(1,557.68 \mathrm{~kg} / \mathrm{cm}^{2}\right)$ dan keteguhan tekan sejajar serat $\left(491.35 \mathrm{~kg} / \mathrm{cm}^{2}\right)$, kayu kumea batu tergolong kayu kelas kuat II, (Tabel 4).

Tabel 3. Nilai rata-rata sifat mekanis kayu kumea batu (Manilkara merrilliana) Table 3. Mean values of mechanicalproperties of kumea batu (Manilkara merrilliana) wood

\begin{tabular}{|c|c|c|c|c|c|c|}
\hline \multirow[t]{2}{*}{ No. } & \multirow[t]{2}{*}{$\begin{array}{c}\text { Sifat mekanis } \\
\text { (Mechanical properties) }\end{array}$} & \multirow[t]{2}{*}{$\begin{array}{l}\text { Satuan } \\
\text { (Unit) }\end{array}$} & \multicolumn{3}{|c|}{$\begin{array}{l}\text { Ketinggian posisi kayu dalam } \\
\text { batang dari permukaan tanah } \\
\text { (Height of wood position in the } \\
\text { trunk from the ground) }\end{array}$} & \multirow[t]{2}{*}{$\begin{array}{c}\text { Rata-rata } \\
\text { (Average) }\end{array}$} \\
\hline & & & $\begin{array}{l}\text { Pangkal } \\
\text { (Bottom) }\end{array}$ & $\begin{array}{l}\text { Tengah } \\
\text { (Middle) }\end{array}$ & $\begin{array}{l}\text { Ujung } \\
(\text { Top })\end{array}$ & \\
\hline 1. & $\begin{array}{l}\text { Keteguhan lentur pada batas } \\
\text { Proporsi (Bending strength at } \\
\text { proporsional limit) }\end{array}$ & $\mathrm{kg} / \mathrm{cm}^{2}$ & 627,26 & 623,12 & 598,83 & 616,40 \\
\hline 2. & $\begin{array}{l}\text { Keteguhan lentur pada batas } \\
\text { Patah (Bending strength at } \\
\text { failure) }\end{array}$ & $\mathrm{kg} / \mathrm{cm}^{2}$ & $1.568,16$ & $1.557,80$ & $1.547,07$ & $1.557,68$ \\
\hline 3. & $\begin{array}{l}\text { ModulusYoung } \\
\text { (Young's modulus) }\end{array}$ & $\mathrm{kg} / \mathrm{cm}^{2}$ & $9.803,70$ & $9.053,25$ & $8.732,98$ & $9.196,65$ \\
\hline 4. & $\begin{array}{l}\text { Keteguhan tekan sejajar serat } \\
\text { (Compression strength parallel } \\
\text { to the grain) }\end{array}$ & $\mathrm{kg} / \mathrm{cm}^{2}$ & 544,62 & 470,04 & 459,39 & 491,35 \\
\hline 5. & $\begin{array}{l}\text { Keteguhan tekan tegak lurus } \\
\text { serat (Compression strength } \\
\text { perpendicular to the grain) }\end{array}$ & $\mathrm{kg} / \mathrm{cm}^{2}$ & 227,15 & 206,70 & 188,87 & 207,57 \\
\hline 6. & $\begin{array}{l}\text { Keteguhan geser sejajar serat } \\
\text { (Shear strength parallel to the } \\
\text { grain) }\end{array}$ & $\mathrm{kg} / \mathrm{cm}^{2}$ & 81,68 & 73,71 & 72,64 & 76,01 \\
\hline 7. & $\begin{array}{l}\text { Kekerasan sisi } \\
\text { (Side hardness) }\end{array}$ & $\mathrm{kg} / \mathrm{cm}^{2}$ & 628,14 & 583,20 & 540,66 & 584,00 \\
\hline 8. & $\begin{array}{l}\text { Keteguhan pukul } \\
\text { (Impact bending strength) }\end{array}$ & $\mathrm{kgm} / \mathrm{cm}^{2}$ & 44,17 & 40,75 & 39,37 & 41,43 \\
\hline
\end{tabular}


Untuk mengetahui apakah terdapat perbedaan kelas kuat kayu pada berbagai posisi ketinggian dalam batang, maka dilakukan perhitungan dengan menggunakan nilai berat jenis kering udara, keteguhan lentur pada batas patah, dan keteguhan tekan sejajar serat seperti pada Tabel 4.

Tabel4. Klasifikasi kekuatan kayu pada berbagai ketinggian dalam batang pohon kumea batu (Manilkara merrilliana)

Table4. Strength classification of wood at various heigth position in the trunk of kumea batu (Manilkara merrilliana) tree

\begin{tabular}{|c|c|c|c|c|c|c|}
\hline \multirow[t]{2}{*}{ No. } & \multirow[t]{2}{*}{$\begin{array}{c}\text { Sifat kayu } \\
\text { (Woodproperties) }\end{array}$} & \multirow[t]{2}{*}{$\begin{array}{r}\text { Satuan } \\
\text { (Unit) }\end{array}$} & \multicolumn{3}{|c|}{$\begin{array}{l}\text { Ketinggian posisi kayu dalam } \\
\text { batang dari permukaan tanah } \\
\text { (Height of wood position in the } \\
\text { trunkfrom the ground) }\end{array}$} & \multirow[t]{2}{*}{$\begin{array}{l}\text { Rata-rata } \\
\text { (Average) }\end{array}$} \\
\hline & & & $\begin{array}{l}\text { Pangkal } \\
\text { (Bottom })\end{array}$ & $\begin{array}{l}\text { Tengah } \\
\text { (Middle) }\end{array}$ & $\begin{array}{l}\text { Ujung } \\
(\text { Top })\end{array}$ & \\
\hline 1. & $\begin{array}{l}\text { Berat jenis kering udara } \\
\text { (Air dry specific gravity) }\end{array}$ & & 0,95 & 0,91 & 0,89 & 0,92 \\
\hline 2. & $\begin{array}{l}\text { Keteguhan lentur pada batas } \\
\text { patah } \\
\text { (Bending strength at failure) }\end{array}$ & $\mathrm{kg} / \mathrm{cm}^{2}$ & $1.568,16$ & $1.557,80$ & $1.547,07$ & $1.557,68$ \\
\hline 3. & $\begin{array}{l}\text { Keteguhan tekan sejajar serat } \\
\text { (Compression strength parallel } \\
\text { to the grain) }\end{array}$ & $\mathrm{kg} / \mathrm{cm}^{2}$ & 544,62 & 470,04 & 459,39 & 491,35 \\
\hline & $\begin{array}{l}\text { Kelas kuat kayu } \\
\text { (Wood strength class) }\end{array}$ & - & II & II & II & II \\
\hline
\end{tabular}

Dari Tabel 4 di atas dapat diketahui bahwa kayu pada bagian pangkal, tengah dan ujung batang kumea batu mempunyai kelas kuat sama, yaitu kelas kuat II.

\section{Kegunaan}

Ditinjau dari struktur anatomi dan sifat fisis mekanis, kumea batu dapat digunakan sebagai bahan bangunan yang tidak terkena langsung panas matahari dan hujan serta kelembaban tinggi, karena kayu ini memiliki penyusutan yang sangat tinggi dan mudah retak. Kumea batu tergolong kayu kelas kuat II, oleh karena itu dapat digunakan untuk komponen bangunan yang menerima beban yang berat misalnya : kuda-kuda, kaso, reng, dan kusen. Disamping itu, kayu kumea batu memiliki corak yang indah, serat lurus, tekstur halus dan mengkilap sehinga baik untuk moulding rangka/daun pintu dan jendela serta lantai (flooring dan decking), bahan untuk mebel (kursi, meja, almari dan tempat tidur). Kesesuaian penggunaan untuk produk-produk tersebut juga didukung oleh data hasil penelitian pemesinan kayu kumea batu (Asdar, 2007) yang melaporkan bahwa kumea batu memiliki sifat penyerutan, pembentukan, pengemplasan, pengeboran dan pembubutan sangat baik atau memenuhi syarat kelas I. Selain itu, kumea batu tergolong kayu yang keras dan memiliki berat jenis yang 
jURNAL Penelitian Hasil Hutan Vol. 26 No. 2, Juni 2008: 138-147

sangat tinggi sehingga sangat baik untuk arang, sebaliknya kurang baik dan hanya tergolong kedalam kualitas IV sebagai bahan baku pulp dan kertas.

\section{KESIMPULAN}

1. Kumea batu memiliki kayu teras berwarna coklat kemerahan, kayu gubal berwarna coklat muda kemerahan, memiliki corak yang indah, serat lurus, tekstur halus dan mengkilap.

2. Panjang serat kayu tersebut $677,55 \mu \mathrm{m}$, diameter serat $22,15 \mu \mathrm{m}$, diameter lumen $1,94 \mu \mathrm{m}$ dan tebal dinding $10,10 \mu \mathrm{m}$.

3. Kumea batu tergolong kayu sangat berat (berat jenis 0,92) dengan penyusutan sangat tinggi dan kekuatannya tergolong kelas kuat II.

4. Kumea batu tergolong kayu yang kuat, memiliki corak dan warna yang indah sehingga dapat digunakan sebagai bahan bangunan, moulding, mebel, dan sangat baik untuk arang, akan tetapi kurang baik dan hanya tergolong dalam kelas IV sebagai bahan pulp dan kertas.

\section{DAFTAR PUSTAKA}

Anonim. 1976. Vademecum Kehutanan Indonesia. Direktorat Jenderal Kehutanan Departemen Pertanian, Jakarta. Hlm. 43-45.

2003. Standard methods of testing small clear specimens of timber. Japan Industrial Standard (JIS). Tokyo, Japan.

Asdar, M. 2007. Sifat pengerjaan jenis kayu kurang dikenal andalan setempat. Laporan penelitian (tidak diterbitkan). Balai Penelitian dan Pengembangan Kehutanan Sulawesi, Makassar.

Dumanau, J. F. 1982. Mengenal kayu. PT. Gramedia. Jakarta. Hlm. 18.

Haygreen, J.G dan J.L. Bowyer. 1996. Hasil Hutan Dan Ilmu Kayu, Suatu Pengantar. Cetakan Ketiga. Terjemahan S.A. Hadikusumo. Gajah Mada University Press.

Mandang Y. I. dan A. Martawijaya. 1987. Pemanfaatan jenis kayu kurang dikenal. Prosiding Diskusi Pemanfaatan Kayu Kurang Dikenal Tgl 13-14 Januari 1987, Cisarua, Bogor). Badan Penelitian dan Pengembangan Kehutanan, Bogor.

Martawijaya, A. dan I. Kartasujana. 1977. Ciri umum, sifat dan kegunaan jenis-jenis kayu Indonesia . Publikasi Khusus Lembaga Penelitian Hasil Hutan, no. 41. Badan Penelitian dan Pengembangan Pertanian, Departemen Pertanian, Bogor.

Panshin, A. J and C. de Zeeuw. 1980. Texbook of Wood Technology. $14^{\text {th }}$ ed. McGraw-Hill Book Company, New York.

Sass, J. 1958. Botanical Microtechnique. $3^{\text {rd }}$. ed. The Iowa State University Press, Ames, Iowa, USA. 3-77 pp. 
Soerianegara, I and R.H.M.J. Lemmens (ed.). 1994. Plant resources of South-East Asia 5 (1) timber trees: Major commercial timbers. Prosea. Bogor, Indonesia.

Wheeler, E.A., P. Baas and P.E. Gasson (ed). 1989. IAWA List of Miscroscopic features for hardwood identification. IAWA Bulletin n.s. 10 (3) : 219-332. Leiden, Netherlands. 